Journal of Research in Interprofessional

Practice and

Education

Vol. 3.2

August, 2013

Journal of Research in Interprofessional Practice and Education (JRIPE)

Vol. 3.2

(c) 2013

Corresponding author: Betty Cragg, Email: 'bㅁag@uottawa..ca!

\section{Implementing and Sustaining a Rural Interprofessional Clinical Education Program}

\author{
Betty Cragg, EdD, RN; Wilma Jelley, MEd, PT; \\ Mona Burrows, MScN, RN, NP-PHC; \& Kim Dyer, BScPT, PT
}

\begin{abstract}
Background: After a successful pilot project introducing interprofessional (IP) clinical education in a rural hospital, expansion to other rural hospitals was attempted. Despite enthusiasm for the pilot project and funding, the university-based project team had difficulty persuading administrators and staff to become involved or to maintain the project. Of 9 institutions, 2 implemented and sustained the project for more than 2 years, 2 initiated but dropped it, and 5 declined.

Methods and Findings: A qualitative, interpretive description study was conducted to identify facilitators and barriers to implementing an IP clinical education program in rural settings. Semi-structured interviews were conducted with representatives of organizations that sustained the project, dropped out, or never participated.

Using the National Health Service Sustainability Model we identified the staff, organization, and process factors that affected the program implementation. Three staff roles were required for success: sponsor, champion, and gatekeeper. Organizational factors included infrastructure to identify participants and perceived project enhancement of organizational values. Process factors included organizational benefits, compatible priorities, and adaptability.

Conclusions: Introduction of IP education to rural institutions requires complex combined factors. However, continuation of the project at two sites demonstrates that when IP education is valued and sustainability factors are present, staff will maintain it.
\end{abstract}

Keywords: Interprofessional education; Rural interprofessional; Sustainability; NHS sustainability model

\section{Introduction}

Interprofessional education (IPE) has been recognized as a means of promoting interprofessional care (IPC) and attaining the advantages of improved communication, better patient care and outcomes, and increased job satisfaction among health professionals [1]. IPE in clinical settings can promote IPC and patient safety [2], as well as encourage recruitment and retention of graduates, especially in rural settings [3-5].

For this study, IPE is defined as occurring "when two or more professions learn with, from, and about each other to improve collaboration and the quality of care" [6, para. 1]. Clinical IPE occurs when IPE activities take place during healthcare students' practicum experiences [7]. IPC is defined as "the provision of comprehensive health services to patients by multiple health caregivers who work collaboratively to deliver quality care within and across settings" [1, p. 7].

Successful clinical IPE for pre-licensure students requires co-operation of educators and clinical organizations for implementation and maintenance. While financial support may be available for implementation, there is seldom funding to maintain IPE projects $[8,9]$. Therefore, IPE must be recognized by administrators, 
Implementing and Sustaining RICE

Cragg, Jelley, Burrows, \& Dyer

Journal of Research in Interprofessional Practice and Education

Vol. 3.2

August, 2013 clinicians, and educators as being worth sustaining without financial incentives. In the past few years, federal and provincial governments in Canada have provided funding for IPE and IPC initiatives $[1,10]$. However, with government cutbacks, this funding has been reduced or eliminated. Those who support IPE must examine the conditions necessary to initiate and sustain programs within the clinical placement system. Sustainability is defined as occurring when "the change has become an integrated way of working ... holding the gains and evolving as required - definitely not going back" [11, para. 3].

In this study, the factors that influenced the implementation and sustainability of our Rural Interprofessional Clinical Education (RICE) program in healthcare organizations in Eastern Ontario were examined. Educators who are outsiders to clinical organizations are dependent on institutional conditions and attitudes to implement and sustain IPE clinical placement initiatives. RICE met with mixed success as we sought to expand from the pilot organization to others in the region. To discover reasons for success or failure to implement or maintain the program in the rural healthcare organizations that were approached, members of the RICE project team sought the perceptions of representatives of these organizations.

\section{Review of the literature}

\section{Clinical Interprofessional Education}

Interprofessional education can occur in the classroom or as part of a clinical placement [7]. Clinical IPE experiences may be arranged as an adjunct to students' regular placements in their curricula or as the focus of the clinical experience [12]. The advantage of clinically based IPE is that it allows students from a variety of professional programs to interact in the kinds of settings in which they will practice after graduation [13]. However, Cook et al. [14] discovered organizational challenges to successful implementation and maintenance of clinical IPE that included increased pressure on already over-burdened clinicians, financial limitations, and co-ordination difficulties.

\section{Rural Interprofessional Education}

There have been a number of examples of successful IPE in rural settings, especially in Canada and Australia [15-21]. Rural IPE has been identified as having three advantages: 1) demonstration of IPC is more likely in the rural environment because there are limited numbers of health professionals in rural settings and there may be more breadth of experiences for students [18,22];2) recruitment of future practitioners to rural settings may be improved through IPE projects [18]; and 3) new clinical placement opportunities can be created for healthcare programs that seek to increase enrolment [22]. While there are programs in which students are sent to rural locations to practice $[9,18]$, other programs base their rural teaching in the educational setting, using case studies and simulations, with only short trips to rural environments $[17,21]$. Situations where students not only practice together but live together in rural areas can improve understanding among members of 
3

Implementing and Sustaining RICE

Cragg, Jelley, Burrows, \& Dyer

Journal of Research in Interprofessional Practice and Education

Vol. 3.2

August, 2013 healthcare programs, though there may also be tensions created [18,22]. Financial support may be an issue since travel and accommodation are frequently required as students leave their educational base [22].

\section{Sustainability of changes in healthcare}

Sustainability of changes in healthcare has become a topic of increased interest. There have been a number of models that describe the factors required for sustainability. The National Health Service (NHS) [23] in Britain has developed a model with staff, organization, and process factors, with 10 sub-factors. This model has been used to assess sustainability of healthcare projects in a number of contexts $[24,25]$. Ramirez et al. [26], looking at green sustainability in healthcare, identified environmental considerations as well as sociocultural, financial, organizational capacity, and political commitment as necessary for sustainability. In IPC, Gotlib Conn et al. [27] concluded that if an intervention is to have long-term effects, there must be local ownership of the change and team members must continue to question how to maintain collaborative teamwork. Armitage et al. [2] developed a sustainability model for their IPE project. Their components were staff development, meaningful involvement, and an IPE leader to co-ordinate. In another IPE study, Suter et al. [28] used the Legacy Sustainability Model [29] that included communication, connections, coherence, continuous assessment, commitment, and constructs as key factors. Barr and Ross [8] identified that regulation is required for stable education funding for IPE if it is to become part of mainstream practice. The factors they saw as preventing IPE sustainability in education were: competing claims on teachers, waning commitment to IPE, high teacher turnover, cuts in resources, lack of manager and regulator understanding, withdrawal of top-level support, and marginalization of IPE. Hollenberg [30] identified the following elements as necessary to maintain clinical IPE: a base of evidence; adequate representation and endorsement from all professions, especially medicine; regulations requiring participation; communication and joint planning between clinical and educational institutions; and continuing education. While there are a number of common sustainability factors like commitment of staff and leadership, meaningful participation, and adequate resources, little has been written about the conditions for longer-term sustainability of IPE projects. Pilot projects and curriculum initiatives, including use of simulation, have been described $[9,12,13,15,17-19,21]$, but these tend to be preliminary reports of successful initiatives.

\section{Rural Interprofessional Clinical Education (RICE)}

The RICE program is an example of a rural IPE initiative that was implemented and sustained in some organizations, initiated and discontinued in others, and never started in several organizations that were approached. RICE was developed by university educators from medicine, nursing, rehabilitation sciences, and spiritual care in collaboration with staff from a rural hospital. The overall objective of RICE was to create a sustainable IPE program in rural clinical organizations in Eastern 
4

Implementing and Sustaining RICE

Cragg, Jelley, Burrows, \& Dyer

Journal of Research in Interprofessional Practice and Education

Vol. 3.2

August, 2013
Ontario that already provided clinical placements for pre-licensure students from different professions.

The program was piloted in 2007 in Hospital N, a 60-bed rural hospital. All university health science students assigned for clinical placements in the area were invited to join the weekly RICE sessions facilitated by local clinicians. Funding for the pilot project was obtained from HealthForceOntario, an Ontario government agency. The program was launched with co-operation of hospital administration, clinicians supervising the students, and local facilitators from medicine, nursing, physiotherapy, and spiritual care. Facilitators received IPE training and agreed to lead one or two of the weekly one-hour IPE case discussion sessions that occurred over an eight-week period. Data collected from survey instruments and interviews demonstrated that participants viewed the RICE program as straightforward, easy to implement, and an effective way to promote clinical IPE [19]. All participants were enthusiastic and recommended that all health science students doing placements in the hospital, no matter their educational institution, should be included and that 90 minutes was a more appropriate length for the IPE sessions. There was also an IPC spillover as units in Hospital $\mathrm{N}$ started conducting interprofessional rounds.

In 2008, funding was not renewed, but the project team provided facilitator training to Hospital S, an organization that had expressed an interest in the program. Ten students, on hospital placements from pharmacy, laboratory sciences, and practical nursing programs, were identified and RICE was implemented under local leadership. In 2009, the project team again received funding from HealthForceOntario, this time to expand the RICE program to other organizations. By the time funding was confirmed, there remained only 15 months for recruitment and implementation of RICE in new organizations. This tight time limit created difficulties in recruiting rural organizations. Funding was used for a project co-ordinator, student travel and accommodation, facilitator training, replacement time or honoraria for facilitators, refreshments at RICE sessions, and development of bilingual materials. Manuals for facilitator training [31,32] and case studies for the weekly IPE sessions, based on the work of Hospital N and Hospital S facilitators [33.34], were developed and made available in hard copy and online.

The project co-ordinator approached nine rural organizations. In 2010, the program was repeated at Hospital N and Hospital S. Faculty from College S and College $\mathrm{N}$, two rural-based community colleges, also agreed to participate when their local hospitals were unable to provide RICE within the time limits. In 2011, only Hospital $\mathrm{S}$ carried out RICE and has continued to do so. Hospital N and College $\mathrm{N}$ dropped out. College S has reintroduced RICE in 2012 after some administrative issues in 2011.

The program was perceived by the original participants as straightforward because students were already present at the local organizations for their clinical placements, it required few resources apart from a room and facilitator time, it fit with organizational values of improving patient care and safety, and it involved limited time commitments because facilitators seldom led more than one or two sessions per year [19]. However, it became obvious to the project team that a number of factors were interfering with successful uptake and maintenance of RICE. 
Implementing and Sustaining RICE

Cragg, Jelley, Burrows, \& Dyer

Journal of Research in Interprofessional Practice and Education

Vol. 3.2

August, 2013

\section{Journal of Research in Interprofessional Practice and Education}

Two of the educators from the original project team decided to examine the factors that led to acceptance or rejection of RICE and its maintenance over time. We selected a descriptive qualitative research approach to the research question: "What were the factors that affected implementation and sustainability of the RICE program in rural healthcare organizations?"

\section{Methods}

A qualitative, interpretive description study [35] was developed. Interpretive description is a research perspective particularly suitable for health science professions because it "makes practical sense and generates credible and usable findings" [36, p. 17], without the theoretical overlays that characterize methods like phenomenology or ethnography. Ethics review board approval was obtained from the university and accepted by the rural organizations. Participants from the nine rural organizations were recruited by telephone and with a follow-up email that provided additional information on the research project. After obtaining informed consent from each participant, interviews were conducted by telephone or in person, depending on the participants' preferences and the logistics of rural travel. Representatives of all four organizations that had implemented RICE participated. Administrators in four of the five non-participating organizations agreed to be interviewed. The two researchers conducted semi-structured interviews with administrators or faculty of the organizations that had implemented and sustained RICE (Hospital S and College S), the organizations that had implemented and not maintained RICE (Hospital N and College N), and administrators from four organizations that had declined to participate (Site D 1 to Site D 4). Face-to-face interviews were held at Hospital N, Hospital S, and College S; the other interviews were by telephone. Five of the seven hospital administrators interviewed chose to have a clinical co-ordinator or someone else familiar with the organization's clinical placement system present for the interview.

Semi-structured interview schedules were developed for each of the three categories. Participants from the organizations that had implemented the program were asked open-ended questions exploring their experiences and their perceptions of the facilitators and barriers to RICE, and the results personally and organizationally of participation. Questions for sustaining organizations sought perceptions of why the program had been implemented and maintained. Questions for the agencies that had not been able to maintain RICE explored the reasons for adopting but not continuing it. Representatives of organizations that had declined to participate were asked to describe the reasons and what factors would have to be in place for future participation. Constant comparative analysis [37] led to modification of the interview questions during data collection to reflect emerging patterns.

All interviews were recorded and transcribed. Qualitative interpretive methods [35] were used to analyze the transcripts. Two of the authors independently reviewed all transcripts to develop initial codes and then compared their conclusions. Coding using the methods described by Miles and Huberman [38] led to identification of key themes. After initial descriptive coding, we identified that the 


\section{JRIPE}

6

Implementing and Sustaining RICE

Cragg, Jelley, Burrows, \& Dyer

patterns and themes that were emerging from the data reflected the factors in the sustainability model developed by the National Health Service (NHS) Institute for Innovation and Improvement [23] in the United Kingdom (Figure 1). Since the themes emerging fit the NHS model, the next phase of coding involved sorting the descriptive codes into the model's factors and sub-factors. The NHS model consists of three factors-staff, organization, and process-that play critical roles in the sustainability of initiatives and change in health care. Ten sub-factors add the specific details and characteristics for each of the three factors. The model was developed to identify strengths and assist with planning for sustainability.

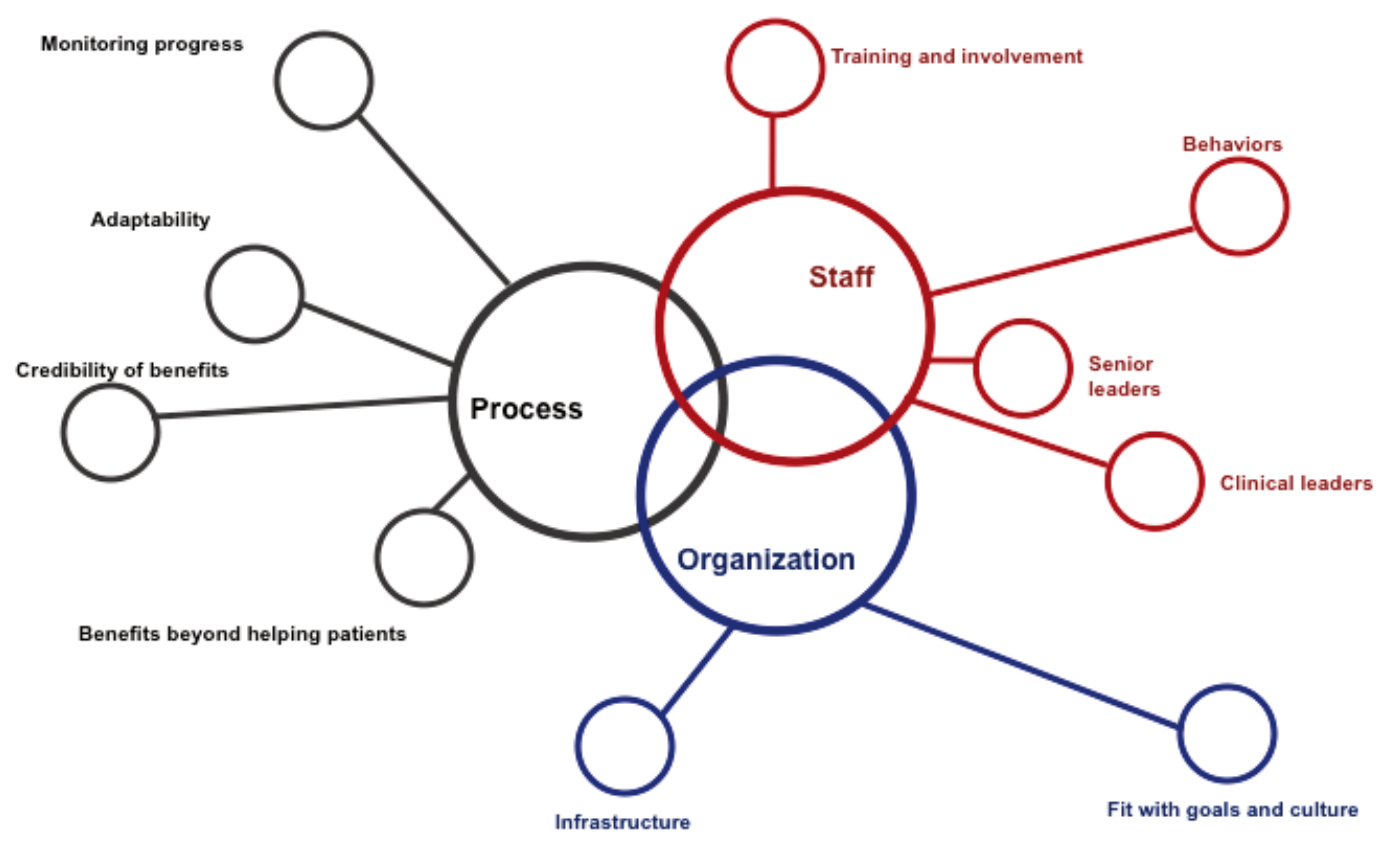

Figure 1: National Health Service Sustainability Model (2007). Used with permission.

\section{Findings}

The results of the data analysis have been presented using the factors and sub-factors from the NHS sustainability model [23]. The results are grouped under staff, organization, and process, the three main factors that predict sustainability, and their respective sub-factors.

\section{Staff}

Within the NHS staff factor, there are four sub-factors that influence staff in sustain-

Journal of Research in Interprofessional Practice and Education

Vol. 3.2

August, 2013 ing a new initiative [23]. The sub-factors are: senior leaders, clinical leaders, training and involvement, and attitudes toward change. According to the NHS framework senior leaders are individuals in positions of power and authority who are invested in the initiative and can be influential to help overcome barriers. Clinical leaders are individuals who can engage clinicians and encourage them to be 
Implementing and Sustaining RICE

Cragg, Jelley, Burrows, \& Dyer

Journal of Research in Interprofessional Practice and Education

Vol. 3.2

August, 2013

\section{Journal of Research in Interprofessional Practice and Education}

involved. Training and involvement identifies that key staff members should be involved from the onset and trained in any new skills that are needed. Attitude toward change refers to the necessity to reduce negative opinions regarding an initiative and to help staff to feel empowered. As well as these components, we identified an additional sub-factor in the staff category, which was gate-keeper.

\section{Senior leaders}

As participants described the actions of senior leaders, it was clear that the essential senior leader role for success in RICE was as sponsor. This leader was someone high in the organization's administration, usually the Chief Executive Officer or VicePresident of Patient Care, who understood the program, valued IPC, and provided moral support for the project. Senior leaders provided resources, encouragement, and recognition for the project. As sponsors, they organized staff development about IPC, in addition to RICE. Participants at various organizational levels revealed that if a senior leader did not understand the project, felt that the organization was already doing enough for IPE and IPC, or believed there were other priorities, those issues took precedence and RICE was either not implemented or not sustained. In situations where communication breakdowns occurred among the project team, clinical leaders, and gatekeepers, senior leaders might not be informed about what was happening and sponsorship of the project could be lost. Participants also indicated that the support of respected administrators and leaders in professions increased the credibility of the project and the likelihood of participation.

You need the facilitating too.... You need that department head kind of team or, and you do need your CEO, and you need your administrative people there to say yes to something you want to do. (Clinical leader Hospital S - sustained RICE)

Often the responses of senior leaders in organizations that did not participate indicated that they had not comprehended that funding was available to support project activities, to provide administrative support, and to compensate for facilitators' time. These senior leaders did not inform potential clinical leaders and clinicians of the opportunity.

Honestly, a lot of things have to do with human resources and how many people are around and people who are available, and in smaller organizations there are ... you've got limited number of resources and you're going to those people all of the time. (Senior leader Site D4 - declined to participate in RICE)

I really would have had to kind of talk with [Vice President] as far as whether we were going to be able to provide the human resource side of it. (Senior leader Site D3 - declined to participate in RICE)

\section{Clinical leaders}

In successful implementations, participants identified that there were clinical leaders 
Implementing and Sustaining RICE

Cragg, Jelley, Burrows, \& Dyer

Journal of Research in Interprofessional Practice and Education

Vol. 3.2

August, 2013
Journal of Research in Interprofessional Practice and Education

or champions of IPE who were essential for the day-to-day running of the project. These champions were usually professionals with credibility within in the organization who were committed to IPC and willing to serve as the internal organizer. They took on the tasks of recruiting facilitators for the weekly sessions, finding and inviting the students, making sure there were available time and space, and ensuring staff training. If the clinical leader was no longer able to fulfill these tasks, the project was not sustained unless the organization's senior leader found a replacement.

The reality is that we all have responsibilities. For RICE we needed leadership or a small committee really to take the lead, take charge. (Clinical leader College S - sustained RICE)

I would say definitely that, also a lack of leadership .... at the time or people who devote any type of time to the project. And not having a clinical person to co-ordinate any of it at the time either. (Clinical leader Site D4 - declined to participate in RICE)

\section{Training and involvement}

Every interested organization was offered facilitator training. The project team led the sessions and a handbook for facilitators was developed that each participant received $[31,32]$. In the successful organizations, the clinical leaders started working with facilitators to provide more training in-house.

It was also important to have the involvement of key members of professional groups.

[Physicians] said, "You'll have go and talk to [MD] because he is in charge of it [medical education]." He said to me, "Do you realize all the things that these people have to do?" And I said right back to him "Do you know how many things our nurses have to do? We need help from you." And he said, “They don't have an hour [for involvement]." (Clinical leader College N - implemented but did not sustain RICE)

\section{Attitudes toward change}

Participants identified role modeling as an important factor for success. If staff were practicing IPC, they wanted to pass the message on to students. New initiatives to help students understand the importance of IPC and the roles of others were created; for example, students were encouraged to spend time in other departments with students and clinicians in other professions, and some hospital units developed interprofessional rounds when they saw what was happening among the students.

Some members of the team are on board, but it is hard to reach the whole team and to develop those processes so that everybody's involved and knowledgeable. It still requires a lot of work (Senior leader Site D1 - declined to participate in RICE)

\section{Gatekeepers}

While the NHS model [23] identified senior leaders and clinical leaders, we also 
Implementing and Sustaining RICE

Cragg, Jelley, Burrows, \& Dyer

Journal of Research in Interprofessional Practice and Education

Vol. 3.2

August, 2013

\section{Journal of Research in Interprofessional Practice and Education}

identified a third important group under the Staff category: gatekeepers. Gatekeepers might be senior or clinical leaders, or administrative staff members. They could be assistants to administrators, clinical placement co-ordinators, or the preceptors who accepted students for supervision. For a program that was initiated outside the organization, this role was crucial. The perceptions and actions of the gatekeeper turned out to be essential to the implementation of RICE within an organization. The RICE project co-ordinator would usually first contact a potential senior leader within an organization, such as the Chief Executive Officer or Vice President. This person often expressed interest, but immediately delegated the contact person role to someone further down the administrative ladder, often someone with responsibility for co-ordinating student placements. This is the gatekeeper. A gatekeeper who was enthusiastic and well-connected had the power to smooth the path for implementation. In the interviews, it was clear that gatekeepers who did not value or understand IPE, or who feared the project would create extra work for them, were reluctant to facilitate access within the organization. Without the support of the gatekeeper, potential clinical leaders might not be made aware of the opportunity, the project team and clinical leaders had difficulty identifying what students were on-site, and students were not informed.

I think at the time there were more students here than we were made aware of, and you're only as good as your gatekeeper. (Clinical leader Hospital $\mathrm{N}$ - implemented but did not sustain RICE)

\section{Organization}

Within the organization factor of the NHS model [23] there are two sub-factors. These sub-factors are that there is a fit with strategic objectives and culture of the organization and an infrastructure for sustainability. According to the NHS framework, fit with organization's culture means that there are clear links between an initiative and organizational goals and vision. Under the sub-factor of infrastructure, descriptions, policies, procedures, and resources to support the initiative must be in place or developed to support the initiative.

\section{Fit with strategic objectives and culture}

Participants reported that the way was smoothed for implementing RICE if the program was seen by administrators and clinicians as supporting the goals and culture of the organization. If staff were already promoting student mentoring and continuing education, particularly for IPE and IPC, RICE was seen as a great fit. If the organization was seen by staff as having other priorities, or had poor student management processes, the RICE initiative was not accepted or maintained.

One of the reasons we didn't get RICE was because we just didn't get buy in. But again, we tried multiple different ways for a buy in from medicine, still no results at all. (Clinical leader College $\mathrm{N}$ - implemented but did not sustain RICE) 


\section{Journal of Research in Interprofessional Practice and Education}

It's [IPC] in our strategic plan, it's in our vision; it's what we are saying that we are. We need to go back to square one and say, "Okay, what do we need to do this? Because this is our mission and we believe it." (Senior leader Hospital N - implemented but did not sustain RICE)

\section{Infrastructure}

Administrators in non-participating organizations often reported they did not believe the project was truly straightforward. They feared that too much administrative time would be involved recruiting facilitators, getting preceptors' co-operation, scheduling student attendance, and booking meetings. They also felt that participation would be an imposition on already over-worked clinicians.

When a project like this comes along, it's always nice to have referencing to make sure we have the capacity of doing it, and sometimes we don't get all the details. Maybe we can miss an opportunity. (Senior leader Site D2 - declined to participate in RICE)

Rural hospitals in Ontario often have poor systems for tracking students scheduled to come to their facilities. Clinicians in different departments make individual arrangements to take students, and often administrators are unaware until the students report to the Human Resources department on their first day. Administrators, senior leaders, or clinical leaders may not know which days students are scheduled to be present. It is therefore hard to predict suitable timing to attract adequate numbers of students to sessions.

It was just the difficulty ... trying to find out when the students were appearing. Nobody was $100 \%$ sure when anybody was coming or going. ... Last year, it was our manpower. ... We just couldn't, didn't have the time to do what was needed to be done, to get it off the ground. (Senior leader Hospital N - implemented but did not sustain RICE)

\section{Process}

In the NHS model under the Process factor there are four sub-factors [23]. The process sub-factors are: the effectiveness of the organization for monitoring progress, adaptability of the initiative, credibility of evidence supporting the initiative, and benefits beyond helping patients. For monitoring, it is necessary to ensure that there is a system in place to continually monitor the initiative and gather feedback. The initiative must be adaptable and able to continue even if there are changes in staff, leadership, or organizational structures. Under the credibility of evidence sub-factor, it is essential to identify and communicate the benefits so that they are obvious to all key stakeholders. It is also necessary to ensure that the initiative brings benefits to staff.

\section{Monitoring progress}

It was important to leaders that updates and news on the project were given regularly to senior leaders and other participants. 
Implementing and Sustaining RICE

Cragg, Jelley, Burrows, \& Dyer

Journal of Research in Interprofessional Practice and Education

Vol. 3.2

August, 2013

\section{Journal of Research in Interprofessional Practice and Education}

We [senior leader and clinical leader] did a poster and then did a talk as well (Clinical leader Hospital S - sustained RICE)

Either I fell right off the radar or what exactly happened? I am shocked because we speak so highly of ourselves that we do this [IPE] and man, we are not doing it at all. (Senior leader Hospital N - implemented but did not sustain RICE)

Another monitoring system for reporting progress is the process and standards for accreditation of hospitals and educational programs. Senior leaders reported they knew that standards for interprofessional practice were coming [40] and reports of reviews from future accreditations would be important to their organizations, but few had taken actions to ensure that reports about IPE and IPC would be positive.

I think, so it becomes mandatory that they have this, that there's going to be certain places that we're never going to get buy in until they're forced.... I'll tell you our hospital is still pretty old school and so it becomes difficult. (Clinical leader College $\mathrm{N}$ - implemented but did not sustain RICE)

\section{Adaptability}

While RICE started with the students of one university within one organization, Hospital N, participants from each implementing organization reported adaptations to make the program its own. For example, the length of sessions was changed, and case studies were modified to better reflect the student mix. College representatives discussed how the program could be improved for the college setting. One hospital was considering implementing RICE for new employee orientation.

\section{Credibility of evidence}

Participants' perceptions of the importance of IPE and IPC were crucial to success. For administrators and staff who were looking for ways to emphasize and improve IPC within their organizations, RICE was valued.

It is time consuming, like there are times where I might spend an hour on IPE, organizing it. ... I think if the system can work, if we can take out the, "I don't know what your role is; you don't know what my role is," to, "I need help with the stroke patient transfer, and at least can we get a time, like 9:30? Can I meet you to do this?" Then you know you're saving [time] ... in the end, it is saving the system to spend a little on this. (Clinical leader Hospital S - sustained RICE)

What we were much attracted to is that we wanted to ensure that we had a framework or way of getting all of our professions around the table to discuss a patient, because that's the only way that we will ensure that our patients smoothly go through the continuum and that it's patient centered. (Senior leader College N - implemented but did not sustain RICE) 
Implementing and Sustaining RICE

Cragg, Jelley, Burrows, \& Dyer

Journal of Research in Interprofessional Practice and Education

Vol. 3.2

August, 2013

\section{Journal of Research in Interprofessional Practice and Education}

\section{Benefits beyond helping patients}

While improved IPC should be beneficial to patients, most of the participants talked about personal and professional benefits. Some also recognized that RICE could make their organizations more attractive to students and therefore assist in staff recruitment. In Hospital S, clinicians reported that graduates had decided to return to work there partly as a result of their RICE experience.

The students all said that they wished they could do it [RICE] more, they all learned something and they all came away from the table with something else; that they wish they could have done it [RICE] for longer. (Clinical leader College $\mathrm{N}$ - implemented but did not sustain RICE)

The skills of approaching other professionals are transferable (Clinical leader, College $S$ - sustained RICE)

I think there was a push to try to get the medical students here for sure and have that rural experience, and ... I think they were encouraged to try this [RICE] as something that would attract the medical students. (Clinical leader Hospital S - sustained RICE)

\section{Discussion}

The NHS Framework [23] proved to be a useful organizer for the data collected in this study. It helped the researchers to identify key factors and their inter-relationships. The presence or absence of the NHS sustainability factors proved crucial to the acceptance and continuation of the project. Our identification of the gatekeeper role in IPE and sustainability has not been clearly articulated before. The attitudes and support of these individuals, whether they were in leadership, clinical, or administrative support roles, proved to be critical to success or failure. To be maintained over time, local ownership of IPE and IPC has to be developed. It has to be recognized as part of the mainstream of practice in clinical as well as educational settings $[8,30]$. Other factors like timing and scheduling influenced success, but external influences had little impact.

We identified the senior leaders as important in implementing and sustaining the project. Exton [39] discussed the need for entrepreneurial behavior to create and sustain change within healthcare organizations. She argued the administrator as internal entrepreneur is important in innovation and acceptance of healthcare change. In our study, the senior leaders who had an entrepreneurial spirit were the ones who embraced and supported RICE. It is also important that senior leaders, administrators, and staff perceive that the benefits of an initiative for IPE and IPC outweigh resistance to change.

Timing proved to be an important factor in the success of the project. While there was money to support the project, it was only available for 15 months and there was only one university term suitable for implementation within that time period. Longer lead time to set up the necessary infrastructure elements would have helped with explaining and promoting the program to administrators and gate 
Implementing and Sustaining RICE

Cragg, Jelley, Burrows, \& Dyer

Journal of Research in Interprofessional Practice and Education

Vol. 3.2

August, 2013

\section{Journal of Research in Interprofessional Practice and Education}

keepers, and to identifying and mobilizing staff who could be clinical leaders and facilitators. Reports from successful organizations could have been used to influence administrators, and funding to support implementation over several terms might have led to greater uptake. Timing of funding availability has been reported as important for other programs where potential participants were excluded because of their inability to mobilize in time [9].

Scheduling has also been identified as an important issue in IPE, particularly when students are being assigned to rural locations [9]. Most often curriculum developers for different health science programs do not plan clinical placement requirements and sequencing to support IPE. In fact, in our programs, clinical placements for some groups of students are deliberately staggered to avoid overburdening clinical sites with too many students at the same time. There may be limited numbers of students in rural placements, partly because of lack of availability of suitable preceptors $[15,20]$. In rural settings, as one of the administrators pointed out, there are small numbers of clinicians to take on new initiatives. Having small, close-knit communities of practitioners is an advantage for IPC, but there may be burnout if IPE overburdens them [20].

External influences were not key factors in deciding whether to implement and maintain RICE. Despite the encouragement of Health Canada [10] and HealthForceOntario [1] in advocating and providing funding for projects, many local administrators were not swayed. Impending IPE and IPC accreditation standards [40] were recognized, but were regarded by many administrators as issues to be dealt with only when the time came. Immediate priorities like pandemic planning, funding cuts, or opening a new hospital took precedence over longer-term concerns.

We anticipate that using the NHS model [23] as a diagnostic tool to assess the capability of an institution to implement and support an IPE initiative, especially one brought to the organization by outsiders, would be a useful predictor of success in implementation and sustainability. Effort and resources could then be most effectively spent on those institutions with the key success factors in place. Subsequent efforts to spread the innovation could focus on dealing with missing factors in other organizations. Peer reports of success in similar organizations may be important in attracting new sponsors and increasing perceived benefits.

\section{Limitations}

This study involved one project in one region in Ontario at a particular time when funding was readily available but there were other priorities for small rural hospitals. There were limited numbers of potential participants, since only nine organizations were approached. However, eight of nine were represented in this study. Caution must be exercised in extrapolating to other situations, but the findings may provide some guidance for others seeking to influence organizations to accept an externally suggested IPE program. 
14

Implementing and Sustaining RICE

Cragg, Jelley, Burrows, \& Dyer
Journal of Research in Interprofessional Practice and Education

Vol. 3.2

August, 2013

\section{Conclusion}

Sustaining an IPE project is particularly difficult when it is initiated from outside the organization. Within an organization, there must be a belief in the value of IPC and IPE and in the program itself among practitioners from more than one profession. There have to be supportive internal senior leaders and clinical leaders, as well as cooperative gatekeepers. Organizational readiness and infrastructure must be in place to maintain an initiative requiring several levels of involvement over time. In this article, we have discussed the factors at play in organizations that were able or unable to sustain an interprofessional initiative. These factors should be assessed before attempting to introduce other interprofessional programs from outside an organization.

\section{References}

1. Health Force Ontario. (2007). Interprofessional care: A blueprint for action. Toronto: Government of Ontario. URL: hittp:_/_www.healthforceontario.ca/_upload/en/whatishfo/ipco20blueprint $\% 20$ final.pdfi [November 15, 2012].

2. Armitage, H., Connolly, J., \& Pitt, R. (2007). Developing sustainable models of interprofessional learning in practice: The TUILIP project. Nurse Education in Practice, 8, 276-282.

3. Russell, M., Clark, M., \& Barney, T. (1996). Changes in attitudes and skills among occupational therapy students attending a rural fieldwork unit. Australian Occupational Therapy Journal, 43, 72-78.

4. Dunbabin, J., \& Levitt, L. (2003). Rural origin and rural medical exposure: Their impact on the rural and remote medical workforce in Australia. Rural and Remote Health, 3(1), 212. URL: http://www.rrh.org.au [November 15, 2012].

5. Yonge, O., Ferguson, L., \& Myrick, F. (2006). Preceptorship placements in Western rural Canadian settings: Perceptions of nursing students and preceptors. Online Journal of Rural Nursing and

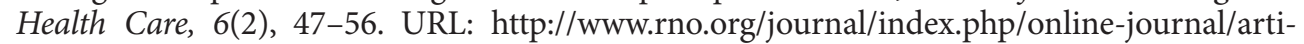
icle/view/10!' [November 15, 2012].

6. Centre for the Advancement of Interprofessional Education (CAIPE). (2002). Defining IPE. URL:

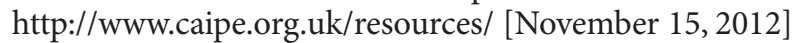

7. Anderson, J.E., Ateah, C., Wener, P., Snow, W., Metge, C. et al. (2011). Differences in pre-licensure interprofessional learning: Classroom vs. practice settings. Journal of Research in Interprofessional Practice and Education, 2(1), 3-24.

8. Barr, H., \& Ross, F. (2006). Mainstreaming interprofessional education in the United Kingdom: A position paper. Journal of Interprofessional Care, 20(2), 96-104.

9. Charles, G., Bainbridge, L., Copeman-Stewart, K., Art, S.T., \& Kassam, R. (2006). The interprofessional rural program of British Columbia (IRPbc). Journal of Interprofessional care, 20(1), 40-50.

10. Health Canada. (2010). Creating healthy supportive, learning workplaces. URL: ihttp://_www.hc-1

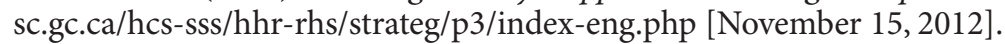

11. National Health Service Institute for Innovation and Improvement (NHS). (2007). Sustainability. URL: hittp:L/www.institute.nhs.uk/ sustainability model/general/wel_come_to_sustainability! himlin' [November 15, 2012].

12. Lait, J., Suter, E., Arthur, N., \& Deutschlander, S. (2011) Interprofessional mentoring: Enhancing students' clinical learning. Nurse Education in Practice, 1, 211-215.

13. Robson, M., \& Kitchen, S.S. (2007). Exploring physiotherapy students' experiences of interprofessional collaboration in the clinical setting: A critical incident study. Journal of Interprofessional Care, 21(1), 95-109. Doi: 10.1080/13561820601076560.

14. Cook, A., Davis, J., \& Vanclay, L. (2001). Shared learning in practice placements for health and social work students in East London: A feasibility study. Journal of Interprofessional Care, 15, 185-190.

15. Dalton, L., Spencer, J., Dunn, M., Albert, E., Walker, J. et al. (2003). Re-thinking approaches to undergraduate health professional education: Interdisciplinary rural placement program. Collegian, 10(1), 17-21.

16. Adams, M.E., Dollard, J., Hollins, J., \& Petkov, J. (2005). Development of a questionnaire measuring student attitudes to working and living in rural areas. Rural and Remote Health, 5, 237.

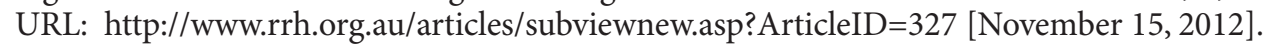

17. Medves, J., Paterson, M., Chapman, C., Young, J., Tata, J. et al. (2008). A new interprofessional course preparing learners for life in rural communities. Rural and Remote Health, 8, 836. URL:

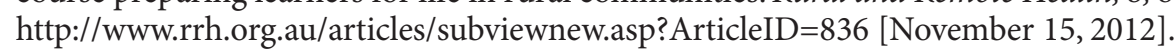


15

Implementing and Sustaining RICE

Cragg, Jelley, Burrows, \& Dyer

Journal of Research in Interprofessional Practice and Education

Vol. 3.2

August, 2013
18. Whelan, J.J., Spencer, J.F, \& Rooney, K. (2008). A “RIPPER” project: Advancing rural interprofessional health education at the University of Tasmania. Rural and Remote Health, 8, 1017. URL:

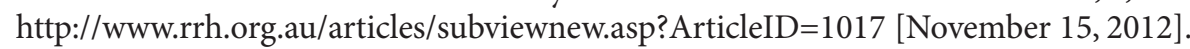

19. Cragg, B., Jelley, W., Hirsh, M., \& Barnes, P. (2010). An interprofessional rural clinical placement pilot project. Journal of Interprofessional Care, 24(2), 207-209.

20. Jacob, E., Barnett, T., Missen, K., Cross, M., \& Walker, W. (2012). Australian clinicians' views on interprofessional education for students in the rural clinical setting. Journal of Research in Interprofessional Practice and Education, 2(2), 219-229.

21. Woodroffe, J., Spencer, J., Rooney, K., Le, Q., \& Allen, P. (2012). The RIPPER experience: A threeyear evaluation of an Australian interprofessional rural health education pilot. Journal of Research in Interprofessional Practice and Education, 2(2), 230-247.

22. Hays, R.B. (2008). Interprofessional education in rural practice: How, when and where? Rural and Remote Health, 8(2), 939. URL:'http://www.rrh.org.au/articles/subviewnew.asp? ArticleİD=939! [November 15, 2012].

23. NHS Institute for Innovation and Improvement. (2006-2012). URL: 'hittp://wwww.institute.nhs.uk 's

24. Ford, J.H., II, Krahn, D., Wisem, M., \& Oliver, K.A. (2011). Measuring sustainability within the veterans' administration mental health system redesign initiative. Quality Management in Health Care, 20(4), 263-279.

25. Higuchi, K.S., Downey, A., Davies, B., Bajnok, I., \& Waggott, M. (2012). Using the NHS sustainability framework to understand the activities and resource implications of Canadian nursing guideline early adopters. Journal of Clinical Nursing, 21(early on-line), 1-10.

26. Ramirez, B., Oetjen, R.M., \& Malvey, D. (2011). Sustainability and the health care manager: Part 1. The Health Care Manager, 30(2), 133-138.

27. Gotlib Conn, L., Oandasan, I.F., Creede, C., Jakubovicz, D., \& Wilson, L. (2010). Creating sustainable change in the interprofessional academic primary care setting: An appreciative inquiry approach. Journal of Research in Interprofessional Practice and Education, 1(3), 284-300.

28. Suter, E., Deutschlander, S., \& Lait, J. (2011). Using a complex systems perspective to achieve sustainable healthcare practice change. Journal of Research in Interprofessional Practice and Education, 2(1), 83-99.

29. Holladay, R. (2005). Legacy: Sustainability in a complex human system. Minneapolis, MN: HSD Institute Press.

30. Hollenberg, I., Reeves, S., Beduz, M.A., Jeffs, L., Kwan, D. et al. (2009). "Mainstreaming” interprofessional education within hospital settings: Findings from a multiple case study. Journal of Research in Interprofessional Practice and Education, 1(1), 10-23.

31. Cragg, B., Jelley, W., Johnstone, B., Hirsh, M., Barnes, P. et al. (2010). Workshop: Facilitating interprofessional education in the rural health care setting. URL: hihttp:[/h !/10393/19716! [November 15, 2012].

32. Cragg, B., Jelley, W., Johnstone, B., Hirsh, M., Barnes, P. et al. (2010). Atelier: Faciliter la formation clinique interprofessionnelle en milieu rural. URL: ihtttp://h hli.hand [November 15, 2012].

33. Cragg, B., Jelley, W., Johnstone, B., Hirsh, M., Barnes, P. et al. (2010). Case studies: Facilitating interprofessional education in the rural health care setting. URL: ihttp://hdl.handle.net 1] 0393 /19718:[November 15, 2012].

34. Cragg, B., Jelley, W., Johnstone, B., Hirsh, M., Barnes, P. et al. (2010). Études de cas: Faciliter la for-

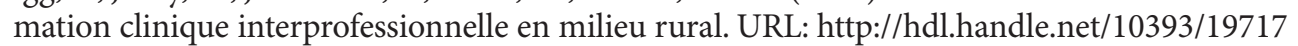
[November 15, 2012].

35. Thorne, S.E. (2009). Interpretive description. Walnut Creek, CA: Left Coast Press.

36. Sandelowski, M. (2000). Whatever happened to qualitative description? Research in Nursing and Health, 23, 334-340.

37. Straus, A., \& Corbin, J. (1990). Basics of qualitative research: Grounded theory procedures and techniques. Newbury Park, CA: Sage.

38. Miles, M., \& Huberman, A.M. (1994). An expanded sourcebook: Qualitative data analysis, $2^{\text {nd }}$ edition. Thousand Oaks, CA: Sage.

39. Exton, R. (2010). Enterprising health: Creating the conditions for entrepreneurial behaviour as a strategy for effective and sustainable change in health services. Journal of Health Organization and Management, 24(5), 459-479.

40. Accreditation of Interprofessional Health Education (AIPHE). (2009). URL:htttp://wwww.cihc.cai laiphelili [November 15, 2012]. 